\title{
Psycho-social Learning Environment from Nurse Students' Perspective
}

\author{
N. A. R. Nettasinghe ${ }^{1, *}$, K. Samarasinghe ${ }^{2}$ \\ ${ }^{1}$ Faculty of Nursing, University of Colombo, Sri Lanka \\ ${ }^{2}$ Faculty of Health Science, University of Kristianstad, Sweden
}

Copyright $\odot 2018$ by authors, all rights reserved. Authors agree that this article remains permanently open access under the terms of the Creative Commons Attribution License 4.0 International License

\begin{abstract}
The quality of the learning environment is vital for the delivery of quality training as there is a proven connection between this environment and the outcome of students' achievements, satisfaction and success. The aim of the study was to explore the experience of student nurses in Sri Lanka about their psycho-social learning environment. The study had a qualitative descriptive design. Data was collected through focus group discussions (FGDs) and individual semi structured interviews from final year nursing students in two Schools of Nursing in Western and Southern provinces in Sri Lanka. Data was analysed through manifest and latent content analysis. Findings showed that supportive supervisors, students' cohesion and social activities influenced students' motivation, satisfaction and confidence thus empowering nurse students in preparing them for their nursing profession. In contrast, theory practice gap, non-supportive supervisors, lack of facilities discouraged and disempowered them and made them feel insecure and frustrated thus making them de-motivated and fed up with their nursing education as a consequence. An empowering learning environment, which strengthens the nurse students' self-confidence and motivation to learn, is therefore a necessity in order to facilitate nurses who can deliver a professional nursing care.
\end{abstract}

Keywords Content Analysis, Psycho-social Learning Environment, Nurse Students, Experiences, Focus Group Discussions, Individual Interviews, Sri Lanka

\section{Introduction}

The psycho-social learning environment covers psychological and social factors that have consequences for student satisfaction, health and the ability to perform at the place of study [1]. Moreover, a good learning environment is vital for the delivery of quality training as there is a proven connection between the environment and valuable outcome of students' achievements, satisfaction and success [2]. To many researchers the educational environment is a multifactorial concept, with a collection of several factors, such as self-perception of learning, self-perception of teachers, academic self-perception, self-perception of atmosphere and social self-perceptions [3]. A growing number of researchers are therefore concerned with school effectiveness and emotional well-being of young people from a psycho-social perspective [4]. In addition, focusing on the well-being of the learner, including attention to different groups according to factors such as gender, physical ability and social economic status will help to address disparities originating from home- and community background [4].This may be of special importance when researching learners from lower-or middle-income countries as there is a relationship between poor quality education, low learning effectiveness and low learning outcomes in low income countries where learners come from poor households or from other marginalized groups

All over the world, educators are attempting to reform the educational environment to make it as student friendly as possible [4]. It is, therefore, important to get feedback regularly from students as to how they experience their learning environment. Although there is much evidence globally about evaluating nursing and other health care professionals' learning environment and psycho-social experiences [4-9], there is no such evidence within the field of Sri Lankan nursing education. However, some evidence has been found in the environment of the medical education field within Sri Lanka for which quantitative data was analysed [11-14]. A qualitative research approach may however gain a deeper insight into the psycho-social learning environment and its consequences on satisfaction, health and the performance of the student at the place of study.

Understanding nurse students' experiences of their psycho-social learning environment is therefore useful research project for nursing education and its development. A learning environment that facilitates students to engage 
in nursing practice is pivotal if nursing is to shift from traditional routine practice to evidence based practice [15]. Moreover [11, 16-17] indicated that nurse educators will benefit from awareness on student's perceptions on how to improve the curriculum and reduce stressors for an improved learning environment. Identifying strengths and weaknesses of the educational environment and understanding how students experience their learning environment will, therefore help the nursing educators in Sri Lanka to build efficient learning environment in their institutions and to achieve better learning outcomes.

\section{Materials and Methods}

The current study which focused on exploring nursing students' experiences of their psycho-social learning environment had an explorative and descriptive design with a qualitative, inductive approach using focus group discussions (FGD) and individual interviews as data collection methods. From an ontological point of view this method is motivated when the inquirer makes knowledge claims based on a constructivist perspective [18]. From an epistemological point of view, knowledge can be obtained through ideas and thoughts that have been expressed by the informants [18]. FGDs are widely used as a data collection technique in qualitative research focusing on words and observations [17] as it helps to obtain the views freely of many individuals in a short time [19]. The group interaction in FGD is expected to produce insight that would be difficult to obtain through individual interview Morgan [20] while in-depth interviews allow researcher to pursue an idea or response in more detail [21]. However, a disadvantage with FGD is that participants may feel unconformable about revealing their inner feelings amongst a group of people [18]. Therefore, face - to -face interviews were carried out in addition to the FGDs with the intention to capture deeper information about topic of the research Combining these two methods were of particular interest in this study as students in Sri Lanka generally do not discuss openly. Moreover, according to [22] triangulation is a powerful technique which enhances the credibility of the findings as it facilitates validation of data through cross verification from two or more sources.

\section{Context of the Study}

There are seventeen nursing schools in Sri Lanka which are managed by the Ministry of Health. Eligibility criteria for admission of the training for those who have passed advanced level examination in science stream, aged between 18-28 years. Students have to be unmarried during the training period. According to health policy, enrolment of male female ratio is 1:20.

Students follow a three year Diploma education in general nursing based on a trimester system of 16 weeks' approved by the Ministry of Health. Student has to study 40.3 hour per week [23]. At present, more than 1800 nursing students are learning in these schools as first, second and third year students [Health report, 2015]. Though criteria of student enrolment and educational curriculum are the same but physical facilities and educational environment differ from school to school [23]. The terms supervisor and teacher are used interchangeably in the Sri Lankan context as an equivalent term for nursing educator.

\section{Selection of Participants}

Students from two nursing schools were chosen for the research; one school in the western province with 126 nurse students in the final year and one nursing school in the southern province with 36 final year nursing students. Altogether 56 nurse students; 32 final year nurse students from the western province and 24 final year nurse students from the southern province were selected randomly through lotteries as participants in the study (Table 1). The students were grouped into five FGDs with eight students in each group and the remaining 16 students were selected for individual interviews. The selected nurse students got the opportunity to select what interview method they wanted to participate in. Out of them 40 students participated in the FGDs and 16 students participated in the individual interviews. All participants were females and their age varied between 23-28 years (average 23-25 years). Majority of the participants were belonging to middle level socio-economic class in Sri Lanka.

Table 1. Overview of participants $n=56$

\begin{tabular}{|c|c|c|c|}
\hline $\begin{array}{c}\text { Nursing } \\
\text { School }\end{array}$ & $\begin{array}{c}\text { Total } \\
\text { population of } \\
\text { final year } \\
\text { students }\end{array}$ & FGDs & $\begin{array}{c}\text { Individual } \\
\text { interview }\end{array}$ \\
\hline Western $(\mathrm{J})$ & 126 & $03(8 \times 3)=24$ & 08 \\
\hline Southern $(\mathrm{M})$ & 36 & $02(8 \times 2)=16$ & 08 \\
\hline
\end{tabular}

\section{Ethical Considerations}

The study was approved by the Training and Research (ET\&R) unit and the Deputy Director General of Ministry Of Health and the principles of the two nursing schools. Furthermore, the empirical study upheld the principles of research ethics in accordance with the declaration of Helsinki [24] (http://www.wma.net/en/30publications/10p olicies/b3/indexBefore collecting data all participants were informed verbally and in writing about the research, its purpose of the study, risks and benefits and that the participation was on a voluntarily basis for which they could withdraw from the study at any time without any negative consequence or harm. Furthermore, that confidentiality was maintained throughout the study by using a serial number for each transcribed data instead of the name of the participant and that only the principle 
investigator and her supervisor had access to the recorded and material which was stored under lock and key. A written, informed consent was taken from each participant.

\section{Data Collection}

The study was conducted within five months. All interviews were tape recorded with the permission of the participants. Both FGDs and individual interviews started with questions about the nurse student's bio-graphic data. In the FGDs which lasted around 60-75 minutes, a tutor who is specialized in mental health and psychiatry nursing participated for note taking and observation of the nurse students' interactions. The individual interviews at respective nursing school lasted around 30-35 minutes.

The tape recordings of the FGDs and the individual interviews were transcribed verbatim and translated to English by RN who is fluent in both Sinhala and English. The transcripts of the FGDs and the individual interviews were read by $\mathrm{RN}$ who compared the transcripts with the assisting tutor's notes and observations.

\section{Data Analysis}

The analysis started by $\mathrm{RN}$ reading the transcribed interviews first of the FGDs and then of the individual interviews, in order to grasp the wholeness of the data. Thereafter the actual analysis of the entire data was started by analysing the transcripts from both the FGDs and the individual interviews together using inductive manifest and latent content analysis which deals with interpretation for which the depth and level of abstraction may vary [25]. Units for analysis so called meaning bearing units were identified. These analysis units were condensed and coded. Similar codes were sorted into sub-categories and similar sub categories were sorted into categories which constitute the manifest content. The categories were reflected upon and discussed with the supervisor, and an overriding theme was composed interpreting the underlying meaning of the entire data which constitutes the latent content of the data material. Two examples of the analysis process are presented in table 2 .

Table 2. Examples of the analysis process

\begin{tabular}{|c|c|c|c|c|c|}
\hline Meaning bearing unit & Condensed meaning unit & Code & Subcategory & Main category & Theme \\
\hline $\begin{array}{l}\text { We have very kind, } \\
\text { enthusiastic teachers and } \\
\text { supportive tutors here } \\
\text { except a very few. They } \\
\text { reassure us all the time } \\
\text { when we have face very } \\
\text { unhappy situation.(M-4) }\end{array}$ & $\begin{array}{l}\text { We have kind and enthusiastic } \\
\text { tutors who reassure as in } \\
\text { unhappy situations. }\end{array}$ & $\begin{array}{l}\text { Supportive } \\
\text { tutors }\end{array}$ & $\begin{array}{r}\text { Feeling } \\
\text { secure }\end{array}$ & $\begin{array}{l}\text { Satisfied and } \\
\text { motivated }\end{array}$ & $\begin{array}{l}\text { Encouraging } \\
\text { and } \\
\text { empowering }\end{array}$ \\
\hline $\begin{array}{l}\text { Tutors always encourage us } \\
\text { to follow patient centered } \\
\text { caring but nurses who are } \\
\text { working in ward follow } \\
\text { functional methods for } \\
\text { caring patients. There is a } \\
\text { theory practice gap here. } \\
\text { Therefore we are always in } \\
\text { trouble in ward doing any } \\
\text { activity. Why do they not } \\
\text { follow what they have } \\
\text { learnt?(M-1) }\end{array}$ & $\begin{array}{l}\text { There is a theory practice gap } \\
\text { due to nurses are not following } \\
\text { patient centered care for } \\
\text { caring in the ward causing } \\
\text { trouble for nurse students }\end{array}$ & $\begin{array}{l}\text { Theory } \\
\text { practice gap }\end{array}$ & $\begin{array}{l}\text { Feeling } \\
\text { insecure }\end{array}$ & $\begin{array}{l}\text { Fed up and } \\
\text { demotivated }\end{array}$ & $\begin{array}{l}\text { Discouraging } \\
\text { and } \\
\text { disempowering }\end{array}$ \\
\hline
\end{tabular}




\section{Findings}

The analysis comprised of one overriding theme and two qualitatively different categories with respective subcategories illustrating the characteristics of the student nurses experiences of their psycho-social learning environment (Table 3). The letter and number within brackets refer to a particular interview person's statement either in the focus group (FGD) or in the individual interview.

Table 3. Overview of the outcome of the data analysis

\begin{tabular}{|c|c|c|}
\hline \multicolumn{3}{|c|}{$\begin{array}{c}\text { Overriding theme: Encouraging and empowering but also } \\
\text { discouraging and disempowering }\end{array}$} \\
\hline Categories & $\begin{array}{c}\text { Satisfied and } \\
\text { motivated }\end{array}$ & $\begin{array}{c}\text { Fed up and de } \\
\text { motivated }\end{array}$ \\
\hline \multirow[t]{3}{*}{ Subcategories } & Feeling secure & Feeling disrespected \\
\hline & Feeling relaxed & Feeling insecure \\
\hline & & Feeling frustrated \\
\hline
\end{tabular}

\section{Encouraging and Empowering but also Discouraging and Disempowering}

Nursing students' experience of their psycho-social learning environment meant that they on the one hand harboured feelings of security and self-confidence in becoming a nurse professional by being encouraged and empowered by their psycho-social environment, but on the other hand, harboured feelings of inadequacy related to the nursing profession but also as an individual by being discouraged and disempowered by their psycho-social environment.

\section{Satisfied and Motivated}

Nurse students felt satisfied and were motivated to become a nurse as they were pleased with their education due to supportive superiors and peers as well as stimulating 'after work' social activities.

\section{Feeling Secure}

Nurse students felt secure during their nursing training due to superiors who supported and reassured them especially in difficult situations. They expressed that their teachers were available whenever they were in need of them. The nurse students also said that the positive attitudes of their teachers' and tutors' made them to open up and discuss not only educational problems but also their personal problems. Moreover, they perceived of superiors' characteristics such as empathy, humbleness, friendliness and taking a sincere interest in the students, to enhance good learning outcomes and to inspire and motivate them to fulfill their personal and professional goals.

\footnotetext{
"We accept a kind and empathetic behaviour from our
} teachers and other staff. Some tutors are good as they are dedicated and punctual. Most of the teachers are very enthusiastic about teaching and it helps to encourage learning" (FGD-1)

The nurse students also said that group assignments influenced the development of group feelings which in turn helped in developing self-esteem and self-confidence. Working together with peers as well as with foreign exchange students, contributed to nurse students' feeling secure, especially during their clinical practice, as they could share experiences, both positive and negative, with their peers.
"Our colleagues are the most supportive person in this environment. Therefore we always like to work with our close friends because it helps to develop strength, courage and security especially in ward" $(M-1)$

\section{Feeling Relaxed}

The nurse students were very interested in social activities in their nursing school as it helped in managing their stress and frustration and induced self-respect as well as a mutual respect for each other. All students expressed that it made them happy to participate in religious and cultural social activities which were organized by the nursing school such as New Year festival, as well as welcome- and farewell parties.

"We like social activities in the school it helps relax our frustrated mind and increase our social dignity (FGD-3)

\section{Fed up and Demotivated}

Nurse students felt fed up with their education and lost their motivation to become a nurse due to non-supportive superiors, a prevailing gap between theory and practice, lack of physical facilities and a dysfunctional organization.

\section{Feeling Disrespected}

The nurse students expressed how they felt disrespected especially during their clinical placement as they felt that they were treated as children by the staff rather than as adults.

"As a young personal we need independence to work, autonomy and respect from seniors. It means that being treated as young girls not like small children" (FGD-2)

Also at the hostel the nurse students felt that they were not treated with respect as superiors' interfered in their personal life.

"Principal and the tutors do not allow us to live freely. It increases our stress and we need to break that rules. We don't get enough respect as a young crowd' (J-1) 
Moreover, they expressed worries about discrimination as they felt that medical students got more recognition and attention than the nurse students.

"Medical students have enough attention in clinical. But no one attended to us... Therefore we feel that we are not valuable personnel in the ward" $(J-5)$

\section{Feeling Insecure}

The lack of integration of theory in clinical practice made the student nurses to feel insecure in clinical situations as they felt torn between the demands of their tutor and the clinical nurses. The nurse students identified that they were in need of a role model in clinical practice because nurses followed task based methods rather than patient centered care which the students had learnt in theory.

"All the time Principal and tutors try to maintain professional standards in front of us when teaching and talking in any other activities but we didn't see same thing in the hospital setting" (FGD-1\&3).

In addition, the nurse students did not get enough opportunities to practice in the clinical setting that made them feel insecure about their skills in taking care of patients suffering from various diseases

"We don't have enough opportunities to practice in clinical as we encounter same cases every day. Therefore we are scared to face new situation" (FGD-3)

The students also meant that there was a shortage of clinical supervisors during their clinical practice. It was therefore difficult for the staff nurses to handle their role as a clinical teacher and attend to the individual needs of each nurse student in addition to their normal responsibilities.

"No supportive people in the ward. Nurses are not helping us to give the opportunities to practice. Therefore, we are afraid to take responsibility for caring the patients." $(J-4)$

\section{Feeling Frustrated}

The nurse students felt frustrated due to lack of facilities which they meant would affect their learning capacity negatively. They expressed that they did not have spaced classrooms, no IT lab and the library was small with few and old books.

"We believe that physical facilities are a very important part in the school but we don't have even good classroom. We like good library with internet facility with computers, good hostel and dining hall." (FGD-3)

Moreover the lack of facilities applied also to their clinical practice.

"We need nurses' support for learning and practice procedures. But we don't have such environment for that. We don't have enough equipment in the ward to practice procedure. Therefore we are highly worried about our exams." $(J-3)$

Their frustration was also directed to teaching methods of their teachers. Most teachers practiced traditional teaching methods when lecturing which were considered as boring and de motivating according to the nurse students.

"We are not satisfied about these teaching methods of tutors as they come and teach us as a tuition class and follow traditional teaching methods. Therefore we like learn in facilitated computer class with gaining new knowledge to become a good nurse. " (FGD-2)

The nurse students' were also frustrated due to the organization set up which had several short comings. They meant that the timetable of the education was not reliable. Sometimes the lectures were cancelled without prior warning or the lecturer were late or did not turn up at all.

"Though they put the time table, most of the time it did not work as schedule. Many times lecture periods are cancelled due to lecturers is not coming." (FGD-3)

\section{Discussion}

This study aimed to explore the experiences of psycho-social learning environment from female nurse students between 23-28 years from a middle level socio-economic background in order to facilitate a proficient learning environment for better learning outcomes of the students. The findings indicated that the psycho-social learning environment of the two nursing schools in Sri Lanka encouraged and empowered nurse students in their education to become professional nurses but also discouraged and disempowered them as illustrated in the two descriptive categories "Satisfied and motivated" and "Fed up and de-motivated". According to Gibbs [26] the concept of empowerment refers to both the process of self-empowerment and to professional support of people, which enables them to overcome their sense of powerlessness and lack of influence, and to recognize and eventually to use their resources and chances. Findings of this study illustrates several factors that enables empowerment thus making the nurse students satisfied and motivated to learn as well as the opposite, disempowering the nurse students making them de motivated and fed up with their nursing education. The interpersonal relationship among nurse students and their peers, tutors and teacher' were found to be a key factor in empowering nurse students to achieve their personal and educational goals. The quality of the interactions between students and their superiors such as tutors, clinical supervisors and ward nurses, were identified as a major cause for student satisfaction. This finding corroborates with [27] and Watson [28] who found that the social context of the clinical practice and the professional interaction among nursing students, faculty 
and staff nurses had an impact on the student learning process. Teachers' attitudes such as a friendly and understanding behaviour, facilitated nurse students' self-confidence about nursing care with a fulfillment of the nurse students' personal and professional goals as a consequence. Similar findings were revealed outcome by teachers responding to students' needs and demonstrating positive attitudes to by [29] who found that teacher's behaviour was associated with student teaching and by [11] who found that a competitive authoritarian stressful environment may de-motivate students and weaken their engagement for the learning process. Similarly [30] on the other hand found that a strong positive relationship between teachers and students, facilitated students' motivation and engagement in their work.

Superiors' support of nurse students in this study was mainly related to the characteristics of the nursing tutors and the clinical supervisors. Many researchers have found that teacher's behaviour and their role highly influences students' satisfaction as well as dissatisfaction and may also induce stress. [31-33]Furthermore[34] described that negative interpersonal interactions interfere with the development of the environmental psycho-social support which corroborates with findings of this study which found that non-supportive superiors disempowered the nurse students especially at their clinical practice, by making them feel disrespected, devalued and even discriminated thus affecting their learning capacity negatively. Hence, training in supervision would be desirable for the nursing supervisor in clinical supervision. This suggestion is further emphasized by the fact that the discrepancy between theory and practice was found to emotionally affect the nurse students negatively as seen in the sub category as Theory-practice gap. As the findings of this study also revealed that the most effective learning took place in clinical practice, provided that nurse students are given opportunities to practice what they have learnt in the classroom under supervision and support, nurse students need role models who can supervise professionally in order to reduce theory practice gap. However, the shortage of opportunities to practice in clinical settings making the nurse students insecure as a consequence, is a real challenge to the psycho-social learning environment. Shortage of clinical practice means that there are not enough opportunities to get experience in relevant nursing fields. As a result of this situation, nurse students are not confident enough in carrying out different nursing procedures. Hence, simulating skill labs could be a solution in order to enhance nurse students' confidence in different nursing procedures.

The relationship between nurse students and their peers; both local and international nurse students, was another contributing factor to nurse students' satisfaction in this study, as it strengthened nurse students' dignity and self-esteem as shown in the subcategory student cohesion. Student group activities should therefore be recommended also in clinical practice as student cohesion could be looked upon as another catalyst in line with Gibbs [25] process of self-empowerment. Similarly, social activities in the nursing school influenced nurse students' self-empowering process positively as these activities were found to be of great importance for stress management as well as for the development of self-respect and social dignity. Interesting social activities related to nursing such as farewell party and welcome party and other special cultural celebrating programme should be introduced in order to further enhance nurse students 'satisfaction and wellbeing.

The organizational system, which includes physical and educational facilities, was yet another factor which influenced nurse students' satisfaction and motivation to learn. Nurse students found the traditional teaching methods which were practiced by tutors or teachers in the theoretical parts of the nursing education as dissatisfactory and de motivating to learn as shown in the subcategory non-supportive superiors, whereas group activities were stimulating and enhanced their motivation to learn as shown in the subcategory student cohesion. Similarly, the lack of computer based learning had a negative effect on their motivation to learn as seen in the subcategory lack of facilities. Hence, a different organizational setup including teaching methods and facilities as well as new teaching methods such as problem solving group activities and critical thinking discussions, and courses incorporating web enhanced teaching strategies will be necessary to facilitate nurse students' learning.

\section{Conclusion and Implications for Practice and Research}

The findings of this study show that the psycho-social learning environment if is utmost importance for nurse students' satisfaction and motivation to learn. The findings can serve as a basis for the development of the nursing education as a whole. The study discusses empowering nurse students through the support of supervisors and peers and by making the education more stimulating through student involving teaching methods. The challenge in this area will be to improve on the quality of the clinical practice by integrating theory and practice as there currently is a shortage of supervisors in clinical practice. Expanded research on nurse students' experiences of their psycho-social learning environment based on identified strategies to improve their psycho-social learning environment will be beneficial for the development of a more student friendly nursing education.

\section{Limitations of the Study}

The study is the first qualitative research in Sri Lanka on nurse students' experiences on their psycho-social learning environment. Limitations of this study mainly refer to the choice of participants as no male nursing students took part in the study. A more equitable gender perspective might 
have surfaced if male nursing students had participated in the study. The transferability of the study may be also be limited because the study was carried out in two different nursing schools, both educating nursing on a diploma level, but with an uneven amount of final year nursing students. The physical and clinical facilities of the two schools may therefore have varied. However, as each category of the data analysis is an objectified abstraction representing a central meaning on a collective level, the findings may be transferable to similar contexts

\section{Acknowledgements}

With gratitude's and appreciation, I wish to acknowledge the support by my the thesis supervisor Dr. Kerstin Samarasinghe, all the lecturers and I wish to acknowledge the support given by Associate prof. Carina Elgan, The programme director of master of health sciences. Further I wish to thank students who participated as informants in both nursing schools and principles of school of Sri Jayawardanapura and Mathara Sri Lanka respectively. Moreover I wish to thank D.D.G. (Education, Training, and Research) and Director of nursing (Education) in Ministry of health Sri Lanka.

\section{REFERENCES}

[1] Skaalvic, W., Normann, H.K. \& Henriksen, N. (2011) Clinical learning environment and supervision: experiences of Norwegian nursing students a questionnaire survey. Journal of Clinical Nursing, vol.15, pp.2259-2294

[2] Nahar,N.,Kabiar,H.,Khan,T.H.,Mohammed,S.\&Nargis,T.(2 010). Students' perception of educational environment of Medical College in Bangladesh, Bangabandhu sheikh mujcb medical university journal, vol.3 (2), pp.97-102

[3] Zandvliet, D. \& Straker, L. (2001). Physical and psychosocial aspects of the learning environment in information technology rich classroom, Ergonomics, vol.44 (9), pp.837-57.

[4] Dapi, N.L., Hornell, L., Janlert, U., Stenlud, H. \& Larsson, C. (2010)Energy and nutrient intakes in relation to sex and socio-economic status among school adolescents in urban Cameroon Africa, Public Health Nutrition,pp.1-10.

[5] Harden, R.M. (1986) Approaches to curriculum planning ASME medical education, Medical education, vol.20 (21), pp.458-466.

[6] Gwele, N.S. \& Dana, N. (1998). Perception of Nurse Students of their personal and academic development during placement in the community as a clinical learning environment. Journal of the Democratic Nursing Organization of South Africa, 21 (1), pp. 58-64

[7] Frenzel, A.C., Retrun, R. \& Goetz, T. (2007). Perceived learning environment and students' mathematics classroom. Learning and Instruction, 17, pp. 478-493.available from: www. Elsevier.com /locate/learninstruc

[8] Abraham, R. (2008). Students' perception of learning environment in an Indian Medial school, BMC Medical Education, pp.1-5. Available from http://www.biomedicent ral.com/14726920/8/20

[9] Dunn, S.V. \& Hansford, B. (2008). Undergraduate nursing students' perceptions of their clinical learning environment. Journal of Advanced Nursing, 25(60), pp. 1299-1306.

[10] Brown, T., Williams, B. \& Lynch, M. (2011). The Australian DREEM evaluating student perceptions of academic learning environment within eight health science courses. International Journal of Medical Education, 2, pp.94-101.

[11] Jiffery, M.T., McAleer, S., Fernando, S. \& Marasinghe, R.B. (2005). Using the DREEM questionnaire to gather baseline information on an evolving medical school in Sri Lanka. Medical Teacher, 27(4), pp. 348-52.

[12] Chandrathilake, M.N. \& De Silva, N.R. (2009). Identifying poor concordance between the planned and the hidden curriculum at time of curriculum change in a Sri Lanka Medical School using Dundee ready educational environment measures. South East Asian Journal of Education, 3, pp. 15-19.

[13] Lokuhetty, M.D.S. (2010). Student's perception of the educational environment in a Medical faculty with innovative curriculum in Sri Lanka, South East Journal of Medical Education, 4 (1), pp.9-16.

[14] Hamid, H., Bigdeli, S., Pakpour, V. \& Aalaa, M. (2013). Nursing students' perception of their educational environment based on DREEM Model in an Iranian university. The Malaysian Journal of Medical Sciences, 20(4), pp.56-63.

[15] Kohli,V \& Dhaliwal, U.(2013)Medical students perceptions of the educational environment in a medical college in India: Across sectional study using the Dundee Ready Educational Environment questionnaire, Journal of Educational Evaluation for Health Professions, vol.10

[16] Fooladi, M. \& Sharief, F. (2007). Assessing nursing students' need to improve nursing education. Journal of Medical Education, 11 (3\&4), pp.103-108.

[17] Polit, D.F. \& Beck, C.T. (2004). Combining qualitative and quantitative approach: Some arguments for mixed methods research. Scandinavian Journal of Educational Research, 56 (2), pp.155-165.

[18] Sharif, F. \& Masoumi, S. (2005). A qualitative study of nursing students experiences of clinical practice. $B M C$ Nursing, 4, Available from www.ncbi.nlm.nih.gov/pmc/artic le/PMC1298307

[19] Hill, Y., Lomas, L. \& Mac Gregor, J. (2003). Students' perceptions of quality in higher education, Quality Assurance in Education. Nurse Education Today, 11(1), pp. $15-20$.

[20] Morgan, D.L. (1996). Focus Groups as Qualitative Research: Sage Publications Newbury Park, p.12-81.

[21] Gill, P., Stewart, K., Treasure, E \& Chadwick, B.(2008) Methods of data collection in qualitative research :interviews and focus groups. British Dental Journal, pp.291-295. 
[22] Guba, E.G. \& Lincoln, Y. S. (1994) competing paradigms in qualitative research, Handbook of Qualitative Research, pp.105-119.

[23] Ministry of Health in Sri Lanka (2007). Annual Health Bulletin, Colombo: Medical statistics unit.

[24] http://www.wma.net/en/30publications/10policies/b3/index. html

[25] Graneheim, V. H. \& Lundman, B. (2004) Qualitative content analysis in nursing research concepts, procedures and measures to achieve trust worthiness, Nurse Education Today, vol.24(2),pp.105-112.

[26] Gibbs, G.R. (1999). Learning how to learn using virtual learning environment for philosophy. Journal of Computer Assisted Learning, 15 (3), pp 221-231.

[27] Chin-Chen, H. \& Sheng Lo, H. (2015). Nursing student satisfaction with an associate nursing program. Nursing Education Perspectives, 36, pp.27-33.

[28] Watson, M. \& Battistich, V. (1998). Enhancing students' social and ethical development in school: An intervention programme and its effects. International Journal of Educational Research, 27, pp.571-586.

[29] Tsai, Y.M., Kunter, M. \& Ludtke, O. (2008). What makes lessons interesting? The role of situational and individual factors in three school subjects. Journal of Educational Psychology, 100(2), pp.460-472.

[30] Ryan, A. \& Kaplan, A. (2007). Early adolescents' perceptions of the classroom social environment, motivational belief and engagement, Journal of Educational Psychology, 99(1), pp.83-98.

[31] Fraser, B.J. (1998). Science learning environment; Assessments, affects and determinants. The international handbook of science education, pp.527-564

[32] Henderson, A. (2006). Student's perception of the psycho social clinical environment: An evaluation of placement models. Nurse Education Today, 26, pp. 564- 571. Available from www.Ncbi.nim.ningov/pubmed/16675069 Accessed (26 0ctober 2013).

[33] Shavelson, R. \& Seidal, T. (2006). Approaches in measuring in learning environments. Learning Environment Research-Springer Journal, 9, pp.195-197.

[34] Kumber, D., Doris, Y. \& Leung, P. (2007). Characterising a teaching and learning environment conductive to making demands on student s while not making their workload excessive. Studies in higher education, 31(2), pp.185-198. 